\title{
WYKAZ PRAC HABILITACYJNYCH I DOKTORSKICH Z PEDAGOGIKI ZA ROK 2017
}

\author{
PRACE HABILITACYJNE
}

\begin{tabular}{|l|l|}
\hline Motywacja do uczenia się uczniów w młodszym wieku szkolnym \\
\hline Data zakończenia & $25 / 01 / 2017$ \\
\hline Autor & Małgorzata Głoskowska-Sołdatow \\
\hline Recenzenci & $\begin{array}{l}\text { Hanna Maria Krauze-Sikorska } \\
\text { Józefa Bałachowicz } \\
\text { Jolanta Anna Bonar }\end{array}$ \\
\hline Jednostka nadająca stopień & $\begin{array}{l}\text { Uniwersytet w Białymstoku } \\
\text { Wydział Pedagogiki i Psychologii }\end{array}$ \\
\hline
\end{tabular}

\begin{tabular}{|l|l|}
\hline \multicolumn{2}{|l|}{$\begin{array}{l}\text { Destygmatyzacja przestępców w świetle Magisterium Kościoła oraz poglądów na resocjalizację; } \\
\text { Kapelan więzienny w procesie resocjalizacji penitencjarnej }\end{array}$} \\
\hline Data zakończenia & $22 / 02 / 2017$ \\
\hline Autor & Kazimierz Antoni Pierzchała \\
\hline Recenzenci & $\begin{array}{l}\text { Kazimierz Pospiszyl } \\
\text { Brunon Hołyst } \\
\text { Jan Śledzianowski } \\
\text { Andrzej Bałandynowicz }\end{array}$ \\
\hline Jednostka nadająca stopień & $\begin{array}{l}\text { Uniwersytet Warmińsko-Mazurski w Olsztynie } \\
\text { Wydział Nauk Społecznych }\end{array}$ \\
\hline
\end{tabular}

Geneza i aspekty rozwoju ruchu freinetowskiego w Polsce w latach 1957-2014 jako przykład nauczycielskiego współdziałania, rywalizacji, oporu i doświadczania ambiwalencji w pracy zawodowej i dzialalności stowarzyszeniowej

\begin{tabular}{|l|l|}
\hline Data zakończenia & $22 / 02 / 2017$ \\
\hline Autor & Małgorzata Kaliszewska \\
\hline
\end{tabular}

\footnotetext{
${ }^{1}$ Wykaz sporządzony na podstawie: https://nauka-polska.pl/ (dostęp: 15.10.2018).
} 


\begin{tabular}{|l|l|}
\hline Recenzenci & $\begin{array}{l}\text { Mirosław Stanisław Szymański } \\
\text { Kazimierz Kossak-Główczewski } \\
\text { Aleksander Stanisław Nalaskowski }\end{array}$ \\
\hline Jednostka nadająca stopień & $\begin{array}{l}\text { Akademia Pedagogiki Specjalnej im. Marii Grzegorzew- } \\
\text { skiej } \\
\text { Wydział Nauk Pedagogicznych }\end{array}$ \\
\hline
\end{tabular}

\begin{tabular}{|l|l|}
\hline \multicolumn{2}{|l|}{ Edukacja aksjologiczna. Zarys problematyki } \\
\hline Data zakończenia & $12 / 04 / 2017$ \\
\hline Autor & Grzegorz Leszek Żuk \\
\hline Recenzenci & $\begin{array}{l}\text { Danuta Iwona Wosik-Kawala } \\
\text { Józef Henryk Górniewicz } \\
\text { Maria Reut }\end{array}$ \\
\hline Jednostka nadająca stopień & Uniwersytet Marii Curie-Skłodowskiej w Lublinie \\
& Wydział Pedagogiki i Psychologii \\
\hline
\end{tabular}

\begin{tabular}{|c|c|}
\hline \multicolumn{2}{|c|}{$\begin{array}{l}\text { Osobowość autorska absolwentów klas Montessori w perspektywie doświadczeń i celów życio- } \\
\text { wych }\end{array}$} \\
\hline Data zakończenia & $12 / 04 / 2017$ \\
\hline Autor & Beata Zuzanna Bednarczuk \\
\hline Recenzenci & $\begin{array}{l}\text { Agnieszka Aleksandra Gromkowska-Melosik } \\
\text { Sabina Guz } \\
\text { Bogusław Marian Śliwerski }\end{array}$ \\
\hline Jednostka nadająca stopień & $\begin{array}{l}\text { Uniwersytet Marii Curie-Skłodowskiej w Lublinie } \\
\text { Wydział Pedagogiki i Psychologii }\end{array}$ \\
\hline
\end{tabular}

\begin{tabular}{|l|l|}
\hline \multicolumn{2}{|l|}{ Taoistyczne, konfucjańskie i zachodnie koncepcje pedagogiczne } \\
\hline Data zakończenia & $08 / 03 / 2017$ \\
\hline Autor & Paweł Aleksy Zieliński \\
\hline Recenzenci & Aleksandra Irena Boroń \\
& $\begin{array}{l}\text { Roman Leppert } \\
\text { Józef Henryk Górniewicz }\end{array}$ \\
\hline Jednostka nadająca stopień & Uniwersytet im. Adama Mickiewicza w Poznaniu \\
& Wydział Studiów Edukacyjnych \\
\hline
\end{tabular}

\begin{tabular}{|c|c|}
\hline \multicolumn{2}{|c|}{$\begin{array}{l}\text { Dla dobra szkoły i „,dla dobra służby”... Kwestie ustrojowe szkolnictwa i sprawy zawodowe na- } \\
\text { uczycieli w czasopismach Towarzystwa Nauczycieli Szkół Średnich i Wyższych oraz Związku Za- } \\
\text { wodowego Nauczycielstwa Polskich Szkół Średnich (1918-1939) }\end{array}$} \\
\hline Data zakończenia & $20 / 06 / 2017$ \\
\hline Autor & Barbara Kalinowska-Witek \\
\hline Recenzenci & $\begin{array}{l}\text { Andrzej Piotr Felchner } \\
\text { Elwira Jolanta Kryńska } \\
\text { Wiesław Mirosław Jamrożek }\end{array}$ \\
\hline
\end{tabular}


Jednostka nadająca stopień

Uniwersytet Marii Curie-Skłodowskiej w Lublinie

Wydział Pedagogiki i Psychologii

\begin{tabular}{|l|l|}
\hline \multicolumn{2}{|l|}{ Ideologia, teoria, edukacja. Myśl Ericha Fromma jako inspiracja dla pedagogiki współczesnej } \\
\hline Data zakończenia & $28 / 06 / 2017$ \\
\hline Autor & Rafał Mariusz Włodarczyk \\
\hline Recenzenci & $\begin{array}{l}\text { Beata Agnieszka Ecler-Nocoń } \\
\text { Tomasz Gmerek } \\
\text { Bogusław Marian Śliwerski }\end{array}$ \\
\hline Jednostka nadająca stopień & $\begin{array}{l}\text { Uniwersytet Wrocławski } \\
\text { Wydział Nauk Historycznych i Pedagogicznych }\end{array}$ \\
\hline
\end{tabular}

Edukacja obywatelska w szkole. Krytyczna analiza dyskursu podręczników szkolnych

\begin{tabular}{|l|l|}
\hline Data zakończenia & $14 / 11 / 2017$ \\
\hline Autor & Violetta Kopińska \\
\hline Recenzenci & $\begin{array}{l}\text { Agnieszka Rypel } \\
\text { Dorota Aleksandra Klus-Stańska } \\
\text { Kazimierz Zbigniew Kwieciński }\end{array}$ \\
\hline Jednostka nadająca stopień & $\begin{array}{l}\text { Uniwersytet Mikołaja Kopernika } \\
\text { Wydział Nauk Pedagogicznych }\end{array}$ \\
\hline
\end{tabular}

\section{PRACE DOKTORSKIE}

\begin{tabular}{|l|l|}
\hline \multicolumn{2}{|l|}{ Studia i studenci III stopnia w zakresie pedagogiki w procesie zmian } \\
\hline Data zakończenia & $17 / 01 / 2017$ \\
\hline Autor & Magdalena Kucińska-Głogowska \\
\hline Promotor & Teresa Hejnicka-Bezwińska \\
\hline Recenzenci & $\begin{array}{l}\text { Józef Henryk Górniewicz } \\
\text { Roman Leppert }\end{array}$ \\
\hline Jednostka nadająca stopień & $\begin{array}{l}\text { Uniwersytet Kazimierza Wielkiego } \\
\text { Wydział Pedagogiki i Psychologii }\end{array}$ \\
\hline
\end{tabular}

\begin{tabular}{|l|l|}
\hline \multicolumn{2}{|l|}{ Pedagogiczny dyskurs psychologii humanistycznej } \\
\hline Data zakończenia & $19 / 01 / 2017$ \\
\hline Autor & Jarosław Roman Marzec \\
\hline Promotor & Tomasz Grzegorz Szkudlarek \\
\hline Recenzenci & $\begin{array}{l}\text { Edyta Zierkiewicz } \\
\text { Małgorzata Lewartowska-Zychowicz }\end{array}$ \\
\hline Jednostka nadająca stopień & $\begin{array}{l}\text { Uniwersytet Gdański } \\
\text { Wydział Nauk Społecznych; Instytut Pedagogiki }\end{array}$ \\
\hline
\end{tabular}




\begin{tabular}{|l|l|}
\hline $\begin{array}{l}\text { Szanse edukacyjne uczniów z niepełnosprawnością intelektualną lekkiego stopnia rozpoczynają- } \\
\text { cych kształcenie w szkołach ogólnodostępnych i specjalnych }\end{array}$ \\
\hline Data zakończenia & $24 / 01 / 2017$ \\
\hline Autor & Joanna Przybyszewska \\
\hline Promotor & Iwona Chrzanowska \\
\hline Recenzenci & $\begin{array}{l}\text { Beata Teresa Jachimczak } \\
\text { Małgorzata Jolanta Sekułowicz }\end{array}$ \\
\hline Jednostka nadająca stopień & $\begin{array}{l}\text { Dolnośląska Szkoła Wyższa } \\
\text { Wydział Nauk Pedagogicznych }\end{array}$ \\
\hline
\end{tabular}

\begin{tabular}{|l|l|}
\hline $\begin{array}{l}\text { Znaczenia moralne nadawane zagadnieniom bioetycznym przez uczniów oraz ich nauczycieli bio- } \\
\text { logii w liceum ogólnokształcącym }\end{array}$ \\
\hline Data zakończenia & $16 / 02 / 2017$ \\
\hline Autor & Anna Kot \\
\hline Promotor & Maria Groenwald \\
\hline Recenzenci & $\begin{array}{l}\text { Dorota Aleksandra Klus-Stańska } \\
\text { Zdzisław Franciszek Aleksander }\end{array}$ \\
\hline Jednostka nadająca stopień & $\begin{array}{l}\text { Uniwersytet Gdański } \\
\text { Wydział Nauk Społecznych; Instytut Pedagogiki }\end{array}$ \\
\hline
\end{tabular}

\begin{tabular}{|l|l|}
\hline \multicolumn{2}{|l|}{ Aksjologiczny wymiar dozoru sprawowanego przez społecznego kuratora sądowego } \\
\hline Data zakończenia & $14 / 03 / 2017$ \\
\hline Autor & Karolina Goede \\
\hline Promotor & Urszula Ostrowska \\
\hline Recenzenci & $\begin{array}{l}\text { Piotr Kostyło } \\
\text { Alicja Barbara Żywczok }\end{array}$ \\
\hline Jednostka nadająca stopień & $\begin{array}{l}\text { Uniwersytet Kazimierza Wielkiego } \\
\text { Wydział Pedagogiki i Psychologii }\end{array}$ \\
\hline
\end{tabular}

\begin{tabular}{|c|c|}
\hline \multicolumn{2}{|c|}{$\begin{array}{l}\text { Recepcja idei dawstwa narządów ex mortuo do transplantacji przez adolescentów w aspekcie } \\
\text { edukacyjnym }\end{array}$} \\
\hline Data zakończenia & $14 / 03 / 2017$ \\
\hline Autor & Nina Katarzyna Woderska \\
\hline Promotor & Roman Leppert \\
\hline Recenzenci & $\begin{array}{l}\text { Katarzyna Borzucka-Sitkiewicz } \\
\text { Mirosław Kowalski }\end{array}$ \\
\hline Jednostka nadająca stopień & $\begin{array}{l}\text { Uniwersytet Kazimierza Wielkiego } \\
\text { Wydział Pedagogiki i Psychologii }\end{array}$ \\
\hline
\end{tabular}

\begin{tabular}{|l|l|}
\hline Uwarunkowania funkcji blogów internetowych w życiu młodzieży szkolnej \\
\hline Data zakończenia & $16 / 03 / 2017$ \\
\hline
\end{tabular}




\begin{tabular}{|l|l|}
\hline Autor & Małgorzata Henryka Dorota \\
\hline Promotor & Alina Maria Rynio \\
\hline Recenzenci & $\begin{array}{l}\text { Janusz Stanisław Miąso } \\
\text { Barbara Maria Kiereś }\end{array}$ \\
\hline Jednostka nadająca stopień & $\begin{array}{l}\text { Katolicki Uniwersytet Lubelski Jana Pawła II } \\
\text { Wydział Nauk Społecznych }\end{array}$ \\
\hline
\end{tabular}

\begin{tabular}{|l|l|}
\hline \multicolumn{2}{|l|}{ Relacje Wojska Polskiego z ludnością cywilną na terenie DOK nr VIII w latach 1921-1939 } \\
\hline Data zakończenia & $24 / 03 / 2017$ \\
\hline Autor & Marek Tadeusz Wawrzynkowski \\
\hline Promotor & Mieczysław Nurek \\
\hline Recenzenci & $\begin{array}{l}\text { Jerzy Marian Przybylski } \\
\text { Waldemar Stanisław Rezmer }\end{array}$ \\
\hline Jednostka nadająca stopień & $\begin{array}{l}\text { Uniwersytet Gdański } \\
\text { Wydział Historyczny }\end{array}$ \\
\hline
\end{tabular}

\begin{tabular}{|l|l|}
\hline \multicolumn{2}{|l|}{ Model kształcenia informatycznego w szkołach ponadgimnazjalnych w społeczeństwie sieci } \\
\hline Data zakończenia & $29 / 03 / 2017$ \\
\hline Autor & Rafał Konrad Głębocki \\
\hline Promotor & Włodzimierz Witold Gogołek \\
\hline Promotor pomocniczy & Wiesław Władysław Cetera \\
\hline Recenzenci & $\begin{array}{l}\text { Janusz Piotr Morbitzer } \\
\text { Bronisław Franciszek Siemieniecki }\end{array}$ \\
\hline Jednostka nadająca stopień & $\begin{array}{l}\text { Akademia Pedagogiki Specjalnej im. Marii Grzegorzew- } \\
\text { skiej } \\
\text { Wydział Nauk Pedagogicznych }\end{array}$ \\
\hline
\end{tabular}

\begin{tabular}{|c|c|}
\hline \multicolumn{2}{|c|}{$\begin{array}{l}\text { Sądowa asysta wychowawcza dla młodzieży we Francji i w Polsce. Studium z pedagogiki porów- } \\
\text { nawczej }\end{array}$} \\
\hline Data zakończenia & $11 / 04 / 2017$ \\
\hline Autor & Paulina Perska-Gradowska \\
\hline Promotor & Piotr Andrzej Stępniak \\
\hline Recenzenci & $\begin{array}{l}\text { Leon Chełmicki-Tyszkiewicz } \\
\text { Maciej Witold Bernasiewicz }\end{array}$ \\
\hline Jednostka nadająca stopień & $\begin{array}{l}\text { Uniwersytet im. Adama Mickiewicza w Poznaniu } \\
\text { Wydział Studiów Edukacyjnych }\end{array}$ \\
\hline
\end{tabular}

\begin{tabular}{|l|l|}
\hline \multicolumn{2}{|l|}{ Rola doświadczenia w tworzeniu wiedzy pedagogicznej } \\
\hline Data zakończenia & $11 / 05 / 2017$ \\
\hline Autor & Leszek Waga \\
\hline Promotor & Marian Walerian Nowak \\
\hline
\end{tabular}




\begin{tabular}{|l|l|}
\hline Recenzenci & $\begin{array}{l}\text { Franciszek Szlosek } \\
\text { Danuta Opozda }\end{array}$ \\
\hline Jednostka nadająca stopień & $\begin{array}{l}\text { Katolicki Uniwersytet Lubelski Jana Pawła II } \\
\text { Wydział Nauk Społecznych }\end{array}$ \\
\hline
\end{tabular}

\begin{tabular}{|l|l|}
\hline Sytuacja szkolna dzieci z Kaukazu w szkolach powiatu bialskiego \\
\hline Data zakończenia & $11 / 05 / 2017$ \\
\hline Autor & Olga Izabela Krasuska \\
\hline Promotor & Alina Maria Rynio \\
\hline Recenzenci & $\begin{array}{l}\text { Jerzy Nikitorowicz } \\
\text { Maria Opiela }\end{array}$ \\
\hline Jednostka nadająca stopień & $\begin{array}{l}\text { Katolicki Uniwersytet Lubelski Jana Pawła II } \\
\text { Wydział Nauk Społecznych }\end{array}$ \\
\hline
\end{tabular}

\begin{tabular}{|l|l|}
\hline Monografia długu jako urządzenia wychowawczego \\
\hline Data zakończenia & $18 / 05 / 2017$ \\
\hline Autor & Piotr Aleksander Kowzan \\
\hline Promotor & Tomasz Grzegorz Szkudlarek \\
\hline Recenzenci & $\begin{array}{l}\text { Joanna Justyna Rutkowiak } \\
\text { Helena Ostrowicka }\end{array}$ \\
\hline Jednostka nadająca stopień & $\begin{array}{l}\text { Uniwersytet Gdański } \\
\text { Wydział Nauk Społecznych; Instytut Pedagogiki }\end{array}$ \\
\hline
\end{tabular}

\begin{tabular}{|l|l|}
\hline $\begin{array}{l}\text { Twórczość plastyczna i teatralna dorosłych osób niepelnosprawnych intelektualnie - wymiar oso- } \\
\text { bisty, kulturowy i społeczny }\end{array}$ \\
\hline Data zakończenia & $14 / 06 / 2017$ \\
\hline Autor & Sabina Kazimiera Pawlik \\
\hline Promotor & Adam Stankowski \\
\hline Recenzenci & $\begin{array}{l}\text { Katarzyna Joanna Parys } \\
\text { Anna Katarzyna Nowak }\end{array}$ \\
\hline Jednostka nadająca stopień & $\begin{array}{l}\text { Uniwersytet Śląski w Katowicach } \\
\text { Wydział Pedagogiki i Psychologii }\end{array}$ \\
\hline
\end{tabular}

\begin{tabular}{|l|l|}
\hline Paradoks sukcesu. Zastój efektywności pracy nauczycieli po awansie zawodowym \\
\hline Data zakończenia & $27 / 06 / 2017$ \\
\hline Autor & Iwona Małgorzata Jankowska \\
\hline Promotor & Kazimierz Zbigniew Kwieciński \\
\hline Promotor pomocniczy & Rozalia Małgorzata Ligus \\
\hline Recenzenci & $\begin{array}{l}\text { Marek Budajczak } \\
\text { Bogusława Dorota Gołębniak }\end{array}$ \\
\hline
\end{tabular}




\begin{tabular}{|l|l|}
\hline Jednostka nadająca stopień & $\begin{array}{l}\text { Dolnośląska Szkoła Wyższa } \\
\text { Wydział Nauk Pedagogicznych }\end{array}$ \\
\hline \multicolumn{2}{|l|}{ Zjawisko wyłaniania się nowych profesji nauczycielskich na przykładzie coachingu } \\
\hline Data zakończenia & $27 / 06 / 2017$ \\
\hline Autor & Marzena Major \\
\hline Promotor & Bogusława Dorota Gołębniak \\
\hline Promotor pomocniczy & Beata Zamorska \\
\hline Recenzenci & $\begin{array}{l}\text { Mirosława Aleksandra Nowak-Dziemianowicz } \\
\text { Wanda Maria Dróżka }\end{array}$ \\
\hline Jednostka nadająca stopień & $\begin{array}{l}\text { Dolnośląska Szkoła Wyższa } \\
\text { Wydział Nauk Pedagogicznych }\end{array}$ \\
\hline
\end{tabular}

\begin{tabular}{|l|l|}
\hline \multicolumn{2}{|l|}{ Bestsellery młodzieżowe w biblioterapii wychowawczej uczniów w wieku dojrzewania } \\
\hline Data zakończenia & $28 / 06 / 2017$ \\
\hline Autor & Kamil Kuracki \\
\hline Promotor & Ewa Maria Kulesza \\
\hline Promotor pomocniczy & Agnieszka Dłużniewska \\
\hline Recenzenci & $\begin{array}{l}\text { Katarzyna Stanisława Krasoń } \\
\text { Bernadeta Szczupał }\end{array}$ \\
\hline Jednostka nadająca stopień & $\begin{array}{l}\text { Akademia Pedagogiki Specjalnej im. Marii Grzegorzew- } \\
\text { skiej }\end{array}$ \\
\hline
\end{tabular}

\begin{tabular}{|l|l|}
\hline \multicolumn{2}{|l|}{ Wolontariat studentów pedagogiki specjalnej a nabywanie kompetencji zawodowych } \\
\hline Data zakończenia & $28 / 06 / 2017$ \\
\hline Autor & Bernadetta Kosewska \\
\hline Promotor & Ewa Maria Kulesza \\
\hline Promotor pomocniczy & Danuta Al-Khamisy \\
\hline Recenzenci & $\begin{array}{l}\text { Jadwiga Kuczyńska-Kwapisz } \\
\text { Zenon Stanisław Gajdzica }\end{array}$ \\
\hline Jednostka nadająca stopień & $\begin{array}{l}\text { Akademia Pedagogiki Specjalnej im. Marii Grzegorzew- } \\
\text { skiej } \\
\text { Wydział Nauk Pedagogicznych }\end{array}$ \\
\hline
\end{tabular}

\begin{tabular}{|l|l|}
\hline \multicolumn{2}{|l|}{ Znaczenie niepelnosprawności rodziców z perspektywy funkcjonowania ich dorosłych dzieci } \\
\hline Data zakończenia & $28 / 06 / 2017$ \\
\hline Autor & Barbara Maria Urbanowicz \\
\hline Promotor & Jerzy Semków \\
\hline Recenzenci & $\begin{array}{l}\text { Beata Ewa Cytowska } \\
\text { Wiesław Marian Ambrozik }\end{array}$ \\
\hline
\end{tabular}




\begin{tabular}{|l|l|}
\hline Jednostka nadająca stopień & $\begin{array}{l}\text { Uniwersytet Wrocławski } \\
\text { Wydział Nauk Historycznych i Pedagogicznych }\end{array}$ \\
\begin{tabular}{|l|l|}
\hline $\begin{array}{l}\text { Miejsce śmierci w ponowoczesnym życiu a edukacyjny potencjał kaszubskich rytuałów okołopo- } \\
\text { grzebowych }\end{array}$ & $29 / 06 / 2017$ \\
\hline Data zakończenia & Aleksandra Marta Kurowska-Susdorf \\
\hline Autor & Maria Teresa Mendel \\
\hline Promotor & $\begin{array}{l}\text { Krzysztof Jakubiak } \\
\text { Agnieszka Aleksandra Gromkowska-Melosik }\end{array}$ \\
\hline Recenzenci & $\begin{array}{l}\text { Uniwersytet Wrocławski } \\
\text { Wydział Nauk Historycznych i Pedagogicznych }\end{array}$ \\
\hline Jednostka nadająca stopień &
\end{tabular}
\end{tabular}

\begin{tabular}{|l|l|}
\hline Doświadczanie podmiotowości uczniów kończących pierwszy etap edukacji szkolnej \\
\hline Data zakończenia & $04 / 07 / 2017$ \\
\hline Autor & Tatiana Daniela Grabowska \\
\hline Promotor & Mariusz Cichosz \\
\hline Promotor pomocniczy & Jolanta Elżbieta Nowak \\
\hline Recenzenci & $\begin{array}{l}\text { Lucyna Dziaczkowska } \\
\text { Bożena Matyjas }\end{array}$ \\
\hline Jednostka nadająca stopień & $\begin{array}{l}\text { Uniwersytet Kazimierza Wielkiego } \\
\text { Wydział Pedagogiki i Psychologii }\end{array}$ \\
\hline
\end{tabular}

\begin{tabular}{|c|c|}
\hline \multicolumn{2}{|c|}{$\begin{array}{l}\text { Między praktyką korekcyjną a readaptacją społeczną skazanych. Rekonstrukcja doświadczeń } \\
\text { życiowych osadzonych mężczyzn }\end{array}$} \\
\hline Data zakończenia & $04 / 07 / 2017$ \\
\hline Autor & Miłosz Paweł Mółka \\
\hline Promotor & Zbigniew Jan Marek SJ \\
\hline Promotor pomocniczy & Małgorzata Kutyła \\
\hline Recenzenci & $\begin{array}{l}\text { Mirosław Kowalski } \\
\text { Tadeusz Mirosław Sakowicz }\end{array}$ \\
\hline Jednostka nadająca stopień & $\begin{array}{l}\text { Akademia Ignatianum w Krakowie } \\
\text { Wydział Pedagogiczny }\end{array}$ \\
\hline
\end{tabular}

\begin{tabular}{|l|l|}
\hline Ochrona dziecka przed przemocą w rodzinie na terenie miasta Ruda Śląska \\
\hline Data zakończenia & $07 / 07 / 2017$ \\
\hline Autor & Jacek Copik \\
\hline Promotor & Anna Katarzyna Nowak \\
\hline Promotor pomocniczy & Andrzej Piotr Czerkawski \\
\hline Recenzenci & $\begin{array}{l}\text { Krystyna Marzec-Holka } \\
\text { Bożena Matyjas }\end{array}$ \\
\hline
\end{tabular}




\begin{tabular}{|l|l|}
\hline Jednostka nadająca stopień & $\begin{array}{l}\text { Uniwersytet Śląski w Katowicach } \\
\text { Wydział Pedagogiki i Psychologii }\end{array}$ \\
\begin{tabular}{|l|l|}
\hline Działalność opiekuńczo-wychowawcza & Zgromadzenia Sług Jezusa w Polsce w latach 1989-2010 \\
\hline Data zakończenia & $21 / 09 / 2017$ \\
\hline Autor & Dorota Frąk \\
\hline Promotor & Marian Surdacki \\
\hline Recenzenci & $\begin{array}{l}\text { Władysława Szulakiewicz } \\
\text { Edward Walewander }\end{array}$ \\
\hline Jednostka nadająca stopień & $\begin{array}{l}\text { Katolicki Uniwersytet Lubelski Jana Pawła II } \\
\text { Wydział Nauk Społecznych }\end{array}$ \\
\hline
\end{tabular}
\end{tabular}

\begin{tabular}{|l|l|}
\hline \multicolumn{2}{|l|}{ Edukacja ekologiczna dzieci w mlodszym wieku szkolnym w Polsce i na Ukrainie } \\
\hline Data zakończenia & $21 / 09 / 2017$ \\
\hline Autor & Marianna Khodakivska \\
\hline Promotor & Adam Maj \\
\hline Recenzenci & $\begin{array}{l}\text { Teresa Zubrzycka-Maciąg } \\
\text { Krystyna Chałas }\end{array}$ \\
\hline Jednostka nadająca stopień & $\begin{array}{l}\text { Katolicki Uniwersytet Lubelski Jana Pawła II } \\
\text { Wydział Nauk Społecznych }\end{array}$ \\
\hline
\end{tabular}

\begin{tabular}{|l|l|}
\hline \multicolumn{2}{|l|}{ Samowychowanie w ujęciu wybranych autorów katolickich XX wieku. Analiza porównawcza } \\
\hline Data zakończenia & $21 / 09 / 2017$ \\
\hline Autor & Elwira Monika Balcer \\
\hline Promotor & Alina Maria Rynio \\
\hline Recenzenci & $\begin{array}{l}\text { Andrzej Jakub Sowiński } \\
\text { Edward Janusz Nycz }\end{array}$ \\
\hline Jednostka nadająca stopień & $\begin{array}{l}\text { Katolicki Uniwersytet Lubelski Jana Pawła II } \\
\text { Wydział Nauk Społecznych }\end{array}$ \\
\hline
\end{tabular}

\begin{tabular}{|l|l|}
\hline \multicolumn{2}{|l|}{$\begin{array}{l}\text { Uwarunkowania dzieciobójstwa w świetle warstwicowej teorii wychowania Stefana Kunowskie- } \\
\text { go. Studium indywidualnych przypadków }\end{array}$} \\
\hline Data zakończenia & $21 / 09 / 2017$ \\
\hline Autor & Agnieszka Lucja Nadzieja-Maziarz \\
\hline Promotor & Lucyna Dziaczkowska \\
\hline Recenzenci & $\begin{array}{l}\text { Mariusz Cichosz } \\
\text { Dorota Kornas-Biela }\end{array}$ \\
\hline Jednostka nadająca stopień & $\begin{array}{l}\text { Katolicki Uniwersytet Lubelski Jana Pawła II } \\
\text { Wydział Nauk Społecznych }\end{array}$ \\
\hline
\end{tabular}




\begin{tabular}{|l|l|}
\hline $\begin{array}{l}\text { Kompetencje i kwalifikacje w zawodach usługowych absolwentów szkół ponadgimnazjalnych } \\
\text { i wyższych w kontekście oczekiwań i potrzeb rynku pracy }\end{array}$ \\
\hline Data zakończenia & $26 / 09 / 2017$ \\
\hline Autor & Beata Mydłowska \\
\hline Promotor & Małgorzata Jolanta Sekułowicz \\
\hline Promotor pomocniczy & Piotr Roman Kwiatkowski \\
\hline Recenzenci & $\begin{array}{l}\text { Stefan Michał Kwiatkowski } \\
\text { Daniel Mariusz Kukla }\end{array}$ \\
\hline Jednostka nadająca stopień & $\begin{array}{l}\text { Dolnośląska Szkoła Wyższa } \\
\text { Wydział Nauk Pedagogicznych }\end{array}$ \\
\hline
\end{tabular}

\begin{tabular}{|c|c|}
\hline \multicolumn{2}{|c|}{$\begin{array}{l}\text { Oferta edukacyjna wybranych szkół wyższych miasta Wałbrzycha a aktualne zapotrzebowanie } \\
\text { lokalnego rynku pracy }\end{array}$} \\
\hline Data zakończenia & $27 / 09 / 2017$ \\
\hline Autor & Małgorzata Urszula Radyńska \\
\hline Promotor & Stefania Maria Walasek \\
\hline Recenzenci & $\begin{array}{l}\text { Zenon Jasiński } \\
\text { Alicja Jadwiga Szerląg }\end{array}$ \\
\hline Jednostka nadająca stopień & $\begin{array}{l}\text { Uniwersytet Wrocławski } \\
\text { Wydział Nauk Historycznych i Pedagogicznych }\end{array}$ \\
\hline
\end{tabular}

\begin{tabular}{|l|l|}
\hline \multicolumn{2}{|l|}{ Społeczno-zawodowe uwarunkowania sytuacji trudnych młodego pokolenia nauczycieli } \\
\hline Data zakończenia & $27 / 09 / 2017$ \\
\hline Autor & Tomasz Staniszewski \\
\hline Promotor & Mirosława Wawrzak-Chodaczek \\
\hline Recenzenci & $\begin{array}{l}\text { Krystyna Wiesława Ferenz } \\
\text { Zenon Jasiński }\end{array}$ \\
\hline Jednostka nadająca stopień & $\begin{array}{l}\text { Uniwersytet Wrocławski } \\
\text { Wydział Nauk Historycznych i Pedagogicznych }\end{array}$ \\
\hline
\end{tabular}

\begin{tabular}{|l|l|}
\hline \multicolumn{2}{|l|}{ Filozofia i pedagogika w dialogu. Pytania o prawdę } \\
\hline Data zakończenia & $28 / 09 / 2017$ \\
\hline Autor & Katarzyna Małgorzata Popek \\
\hline Promotor & Janusz Kaczmarek \\
\hline Recenzenci & $\begin{array}{l}\text { Ryszard Mordarski } \\
\text { Bogusław Marian Śliwerski }\end{array}$ \\
\hline Jednostka nadająca stopień & $\begin{array}{l}\text { Uniwersytet Łódzki } \\
\text { Wydział Filozoficzno-Historyczny }\end{array}$ \\
\hline
\end{tabular}




\begin{tabular}{|l|l|}
\hline \multicolumn{2}{|l|}{ Świadomość pedagogiczna współczesnych rodziców oraz jej źródła } \\
\hline Data zakończenia & $11 / 10 / 2017$ \\
\hline Autor & Patrycja Anna Wesołowska \\
\hline Promotor & Ewa Muszyńska \\
\hline Recenzenci & Grażyna Genowefa Gajewska, Magdalena Piorunek \\
\hline Jednostka nadająca stopień & $\begin{array}{l}\text { Uniwersytet im. Adama Mickiewicza w Poznaniu } \\
\text { Wydział Studiów Edukacyjnych }\end{array}$ \\
\hline
\end{tabular}

\begin{tabular}{|l|l|}
\hline \multicolumn{2}{|l|}{ Pedagogiczne aspekty personalizmu Wojciecha Chudego } \\
\hline Data zakończenia & $24 / 10 / 2017$ \\
\hline Autor & Seweryn Łukasz Leszczyński \\
\hline Promotor & Piotr Stanisław Mazur \\
\hline Promotor pomocniczy & Barbara Grażyna Surma \\
\hline Recenzenci & Alina Maria Rynio, Janina Cecylia Kostkiewicz \\
\hline Jednostka nadająca stopień & $\begin{array}{l}\text { Akademia Ignatianum w Krakowie } \\
\text { Wydział Pedagogiczny }\end{array}$ \\
\hline
\end{tabular}

\begin{tabular}{|l|l|}
\hline $\begin{array}{l}\text { Edukacyjne i socjalizacyjne aspekty kultury popularnej. Obraz osoby z niepelnosprawnością ru- } \\
\text { chową w wybranych utworach sztuki filmowej }\end{array}$ \\
\hline Data zakończenia & $22 / 11 / 2017$ \\
\hline Autor & Alicja Stefania Mironiuk-Netreba \\
\hline Promotor & Witold Jakubowski \\
\hline Recenzenci & Zbyszko Melosik, Agnieszka Katarzyna Ogonowska \\
\hline Jednostka nadająca stopień & $\begin{array}{l}\text { Uniwersytet Wrocławski } \\
\text { Wydział Nauk Historycznych i Pedagogicznych }\end{array}$ \\
\hline
\end{tabular}

\begin{tabular}{|c|c|}
\hline $\begin{array}{l}\text { Wychowanie mlodzieży do } \\
\text { Państwowego Uniwersytet }\end{array}$ & $\begin{array}{l}\text { rodziny na Ukrainie w opinii studentów Dro } \\
\text { lego im. Iwana Franki }\end{array}$ \\
\hline Data zakończenia & $07 / 12 / 2017$ \\
\hline Autor & Oksana Duchak \\
\hline Promotor & Marian Walerian Nowak \\
\hline Recenzenci & Mirosław Kowalski, Barbara Maria Kiereś \\
\hline Jednostka nadająca stopień & $\begin{array}{l}\text { Katolicki Uniwersytet Lubelski Jana Pawła II } \\
\text { Wydział Nauk Społecznych }\end{array}$ \\
\hline
\end{tabular}

\begin{tabular}{|l|l|}
\hline Edukacja domowa jako alternatywa edukacyjna dla dzieci zdolnych \\
\hline Data zakończenia & $14 / 12 / 2017$ \\
\hline Autor & Magdalena Alicja Giercarz-Borkowska \\
\hline
\end{tabular}




\begin{tabular}{|l|l|}
\hline Promotor & Mirosława Aleksandra Nowak-Dziemianowicz \\
\hline Promotor pomocniczy & Tomasz Tokarz \\
\hline Recenzenci & Krzysztof Jan Szmidt, Marek Budajczak \\
\hline Jednostka nadająca stopień & $\begin{array}{l}\text { Dolnośląska Szkoła Wyższa } \\
\text { Wydział Nauk Pedagogicznych }\end{array}$ \\
\hline
\end{tabular}

\begin{tabular}{|l|l|}
\hline \multicolumn{2}{|l|}{ Korzystanie z Internetu a preferowane style życia uczniów kieleckich szkól średnich } \\
\hline Data zakończenia & $14 / 12 / 2017$ \\
\hline Autor & Magdalena Buzor \\
\hline Promotor & Sławomir Koziej \\
\hline Promotor pomocniczy & Marzena Maria Pękowska \\
\hline Recenzenci & Wojciech Piotr Walat, Alina Maria Rynio \\
\hline Jednostka nadająca stopień & $\begin{array}{l}\text { Uniwersytet Jana Kochanowskiego w Kielcach } \\
\text { Wydział Pedagogiczny i Artystyczny }\end{array}$ \\
\hline
\end{tabular}

\begin{tabular}{|l|l|}
\hline $\begin{array}{l}\text { Nabywanie kompetencji do samostanowienia przez uczniów z niepelnosprawnością intelektualną } \\
\text { w procesie zróżnicowanego kształcenia }\end{array}$ \\
\hline Data zakończenia & $14 / 12 / 2017$ \\
\hline Autor & Anna Suchon \\
\hline Promotor & Joanna Kruk-Lasocka \\
\hline Recenzenci & $\begin{array}{l}\text { Zdzisława Janiszewska-Nieścioruk, Aniela Ludwika Ko- } \\
\text { rzon }\end{array}$ \\
\hline Jednostka nadająca stopień & $\begin{array}{l}\text { Dolnośląska Szkoła Wyższa } \\
\text { Wydział Nauk Pedagogicznych }\end{array}$ \\
\hline
\end{tabular}

